\title{
This is a narrative review of the functional evaluation of clubfoot treatment with gait analysis
}

\author{
Lori A. Karol ${ }^{1 *}$, Kelly A. Jeans ${ }^{2}$ \\ ${ }^{1}$ Children's Hospital Colorado, Aurora, Colorado, USA; ${ }^{2}$ Scottish Rite for Children, Dallas, Texas, USA \\ Contributions: (I) Conception and design: LA Karol; (II) Administrative support: None; (III) Provision of study material or patients: None; (IV) \\ Collection and assembly of data: Both authors; (V) Data analysis and interpretation: Both authors; (VI) Manuscript writing: Both authors; (VII) Final \\ approval of manuscript: Both authors. \\ Correspondence to: Kelly A. Jeans, MS. Scottish Rite for Children, 2222 Welborn, Dallas, TX 75219, USA. Email: kelly.jeans@tsrh.org.
}

\begin{abstract}
Clinicians worldwide have embraced Ponseti's nonoperative approach in the treatment of clubfoot, primarily due to ubiquitous reports of successful outcomes. A crucial component in this measured success, has come from researchers assessing long-term physical function following nonoperative treatment. Gait analysis has been instrumental in objectively evaluating lower extremity kinematics and kinetics while plantar pressures demonstrate the load bearing patterns experienced in the foot. As technology improves, our ability to evaluate function can take place both in the laboratory setting, and in the community. For over 20 years, our institution has been studying the gait patterns of children treated for clubfoot. After adopting the nonoperative approach, we established a prospective research program that has allowed us to study functional outcomes in the very young walker, through growth to adolescents, and finally at skeletal maturity. We have seen over 450 children treated for clubfoot in the Movement Science Lab, for over 1,250 gait assessments over the span of this study. Early results in 105 children (154 feet) treated nonoperatively for clubfoot, showed $56 \%$ of children had normal sagittal plane ankle kinematics, however an incidence of $48 \%$ of Ponseti feet had increased dorsiflexion in stance phase, leading us to wonder if this was the result of the tenotomy. Intermediate follow up at age 5 years, showed that the incidence of increased dorsiflexion was reduced (24\%) and ankle power did not appear to be affected ( $>0.05$ compared to controls). The research highlighted in this paper presents the application of functional evaluation through growth and the long-term effects of nonoperative treatment on gait and function. This is a review of the functional outcome studies from our experience at Scottish Rite for Children.
\end{abstract}

Keywords: Clubfoot; gait analysis; Ponseti; talipes equinovarus; French physiotherapy

Submitted Oct 22, 2020. Accepted for publication Mar 12, 2021.

doi: $10.21037 /$ atm-20-6922

View this article at: http://dx.doi.org/10.21037/atm-20-6922

\section{Introduction}

Over the last twenty years, there has been a radical change in the treatment of idiopathic clubfoot, starting with primary surgical intraarticular release and now favoring nonoperative treatment for the most part, as advocated by Ponseti and Dimeglio (1-6). Such a revolution has been supported by advanced evaluation of the results of surgical and nonoperative treatment. While early clinical results of clubfoot treatment were limited to radiographic review and reoperation rates (1,7-10), current studies favor functional outcome measures including gait analysis (11-34), pedobarography (35-52), strength measures $(14,16,31,47)$, and parent/patient perceived functional outcomes reports $(8,16,27,30,31,37,38,47,48,53)$. This paper will describe our

* Present address: Children's Hospital Colorado. 13123 East 16th Ave., Aurora, Colorado USA. 
experience at Scottish Rite for Children, in the assessment of functional outcomes of the child with clubfoot, from the gait analysis laboratory to more recent evaluations of community ambulation and participation.

We present the following article in accordance with the Narrative Review reporting checklist (available at http:// dx.doi.org/10.21037/atm-20-6922).

\section{History}

Functional assessment of clubfoot was initially published by Brand in 1981 (54). He observed the center of pressure as patients with treated clubfeet walked across a pressure sensitive mat. Aronson, et al. then studied 29 patients with idiopathic clubfoot (average 10 years; range 4-31 years) who had undergone posteromedial release (55). They found a high incidence (42\%) of ankle stiffness during gait and persistent intoeing. Also associated with clubfoot was a weakness in gastroc-soleus strength.

In 1994, we began our journey studying gait patterns in 23 children with unilateral idiopathic clubfoot with an average follow-up of 11 years, following posteromedial release (14). All these patients were considered to be successful in that further surgery was not being considered. We studied 3-dimensional (3D) kinematics and kinetics gathered during gait at a self-selected walking speed. Diminished dynamic ankle range of motion was found during gait in 20 of 23 patients. Equinus, defined as limited dorsiflexion during the second rocker of gait, was present in $43 \%$ of patients. More worrisome was calcaneus gait (the inability to push off at the transition from stance to swing phase), which was present in $13 \%$ of the 23 patients. Diminished push-off power was found in $78 \%$ of patients, and $27 \%$ demonstrated weakness in isokinetic gastroc-soleus strength, in comparison to their contralateral limb. An internal foot progression angle was present in $65 \%$ of the children. At the knee, differences included increased valgus, mild hyperextension, as well as decreased quadriceps strength in the ipsilateral knee. A follow-up study by Davies, et al. echoes similar deviations at the ankle $(16,17)$, adding additional analysis of the contra-lateral limb in unilateral clubfoot patients, reporting significantly diminished dorsiflexion at the ankle compared to age matched controls (17). We concluded that, even in our asymptomatic population, there were longterm disturbances in gait following posteromedial release.

Using this data as an impetus, we embarked on a nonoperative program of management for newborns with idiopathic clubfoot, first implementing the French physiotherapy program (French PT) (56) described by Bensahel (3) and popularized by Dimeglio (6). Our initial review of patients treated with the French PT program included 90 children with 127 idiopathic clubfeet (22). In this cohort, 52 clubfeet treated nonoperatively with the French PT method were compared to 75 clubfeet that underwent surgical correction. Gait results at age 2 years, showed an increased incidence of calcaneus (increased dorsiflexion in stance and decreased plantarflexion at foot off) following posteriomedial release (29\%) compared to the French PT nonoperative feet $(8 \% ; \mathrm{P}=0.005)$. Similar results were reported by Hee et al., in children $<5$ years treated with posteriomedial release, who showed increased calcaneus in stance phase $\left(18^{\circ}\right)$ compared to controls $\left(9^{\circ} ; \mathrm{P}=0.04\right)$ (36). In nonoperative French PT feet, normal sagittal plane ankle motion was identified in $54 \%$ of the cohort compared to $39 \%$ in the posteriomedial release feet (22). Residual in-toeing was most common in the posteriomedial release feet despite surgical correction $(45 \%)$, which is commonly reported in the clubfoot literature $(16,19,21,27,36)$. Gait results from this initial group of nonoperative clubfeet were encouraging. More than half the clubfeet treated with the French PT method were shown to achieve a supple foot without the need for surgical intervention at age 2 years.

Shortly after establishing the French PT method, we initiated the Ponseti program (1), presenting our patient families with a choice in treatment course. Since fewer patients were requiring comprehensive intraarticular releases (22), it seemed prudent to prospectively evaluate the functional outcomes of children treated nonoperatively, with either the French PT or the Ponseti method, longitudinally from early walking (age 2 years) to skeletal maturity. A comprehensive protocol was designed to include gait analysis and plantar pressures at all ages, from the very young toddler to skeletal maturity, but evaluation was also designed to be more comprehensive as the child matured and was able to follow directions (i.e., kinetics, assessment of gross motor function, patient reported outcome surveys, etc.). By the time they were young adolescents (10 years) and teenagers (skeletal maturity), our ability to study functional outcomes moved outside the lab, into the community. By following the same patient cohort over time, we had the unique opportunity to evaluate the longitudinal effect of nonoperative treatment on function.

In our initial study of nonoperative idiopathic clubfeet, we reviewed the first 105 children who had undergone gait 
analysis at age 2 years (23). El-Hawary et al., compared the nonoperative gait outcomes following the French PT ( $\mathrm{n}=75$ feet) and Ponseti ( $n=79$ feet) programs. Overall, $67 \%$ of French PT feet and $47 \%$ of Ponseti feet had normal sagittal plane ankle motion. In toddlers who had undergone Ponseti casting, excessive dorsiflexion during stance phase was found in $48 \%$ of feet, compared to those who were treated with the French PT technique $(12 \% ; \mathrm{P}<0.001)$. This finding was attributed to the performance of an Achilles tenotomy in the majority of the Ponseti-treated feet (72\%). A significant finding in the French PT feet was a persistence of equinus in $15 \%$ of treated feet, which was likely due to the lack of tenotomy in the French PT protocol. Unsure of the longterm affect, future studies were warranted.

Patients from the same cohort were followed up for gait analysis at the age of 5 years (25). At the initial evaluation at 2 years of age, the study consisted of a clinical evaluation, pedobarograph and 3D kinematics. By the age of five, the patients' step lengths were sufficient to allow for collection of kinetics, as they could now obtain a clean force-plate strike during gait. Kinematics at age five ( $\mathrm{n}=90$ patient, 125 clubfeet) showed that the excessive dorsiflexion identified in the Ponseti group at age two, had for the most part resolved (present in $24 \%$ of Ponseti feet). It was initially hypothesized that the excessive dorsiflexion seen at age 2 years was a result of the full tenotomy performed specifically in the Ponseti feet, causing concern that this may lead to diminished power generation in the gastroc-soleus during gait. Quite the opposite was found. Those feet treated by the Ponseti protocol had the greatest pushoff power generation in third rocker $(2.36 \pm 0.71 \mathrm{~W} / \mathrm{kg})$, perhaps a result of the improved total ankle range of motion $\left(30^{\circ} \pm 5.9^{\circ}\right)$ seen in those feet which had undergone tenotomy. Surgically treated feet had the least power generation $(1.97 \pm 0.62 \mathrm{~W} / \mathrm{kg})$, with diminished ankle range of motion $\left(27.2^{\circ} \pm 4.7^{\circ}\right)$; the result of postoperative scarring. While there were no statistically significant differences in degrees of motion found between Ponseti, French PT or surgical groups, kinematically, nonoperative feet had a greater incidence of normal ankle kinematics and kinetics and less incidence of intoeing ( 30\%), compared to surgical feet (51\%).

While kinematics and kinetics were useful in identifying gait pathology in these young children with clubfeet, 3D gait analysis is labor-intensive, and not all children were able to follow instructions to complete the protocol. Pedobarography emerged as a complementary modality of functional testing that could be used to analyze the status of the clubfoot at any age during gait (33-52). Pedobarograph data can be obtained from a single stride in a young child unencumbered by reflective markers and electromyography leads. The data output is visually simple to understand, and can illustrate overcorrection, with increased hindfoot and medial midfoot pressure, and under-correction, with lack of heel contact and excessive lateralization of pressure to the mid- and forefoot during stance phase $(44,51)$. Pedobarograph data have been used in surgical planning (ex: anterior tibialis tendon transfers), while postoperative studies have documented improved distribution of plantar pressures through the foot $(21,35,37,38,40,45-49,52,54)$.

As described by Ponseti (1), many clinicians acknowledge the necessity for anterior tibialis tendon transfer in a subset of patients who experience recurrence of deformity $(1,2,4,39)$. The gait laboratory can help surgeons assess patients for potential transfer. Kinematic data show internal "foot rotation" in children with over pull of the tibialis anterior muscle leading to internal rotation of the foot relative to the tibia. With concomitant equinus from a tight tendo-Achilles, diminished dorsiflexion is seen in sagittal plane kinematics. Pedobarograph data illustrates increased lateral midfoot and forefoot pressure, and if equinus persists, diminished heel pressure. Finally, electromyography $(24,39,48,57-59)$ can be useful in studying the pattern of anterior tibialis activation during gait. If the anterior tibialis is not electrically active, transfer may not afford any benefit, and bony surgery such as lateral column shortening may, in some cases, be preferred.

There has been increased interest in communitybased measures of function and inquiries as to how these measures compare to gait analysis data. Skeptics of gait analysis (60) have questioned the clinical importance of kinematic and kinetic findings, instead seeking information on gross motor function and community activity. Our center adopted functional testing over ten years ago for assessment of children with idiopathic clubfoot. The first tool used was the Peabody instrument (61). The Peabody test is a validated tool for use in children from infancy to 6 years of age, with age-matched normal values. It assesses gross motor function in three domains. The stationary domain tests ability to stand on one leg and on tiptoe, for example. The locomotion domain tests such activities as hopping on one leg and jumping. Finally, the object manipulation domain tests throwing and kicking a ball. The gross motor quotient (GMQ) is a summation of the three domains, and scores are normalized so that "average" 
function is represented by a score of 50 , meaning that $50 \%$ of similar normal children would score above and below the individual subject. Categorical percentile associations were: Above Average (76-100\%), Average (26-75\%), Below Average (11-25\%) and Poor (0-10\%).

A cohort of 81 children with idiopathic clubfoot from our center completed the Peabody test and gait analysis at age 5 years (30). Overall, the children with clubfeet scored "Average" with a GMQ of $47.6 \%$. In patients who underwent surgical release, 24\% scored Below average or Poor, compared to those who had nonoperative treatment (10\%). Correlations between gait analysis at age 5 and the Peabody test data were determined. Ankle sagittal range of motion did not correlate with the GMQ at age five; however, ankle power did show a weak, positive correlation $(\mathrm{r}=0.29 ; \mathrm{P}=0.010)$. Stationary scores also showed positive correlation to peak ankle plantarflexion $(\mathrm{r}=0.23 ; \mathrm{P}=0.041)$ and ankle power $(\mathrm{r}=0.27 ; \mathrm{P}=0.014)$. The Peabody was easy to administer but is limited in its design; the child can self-select which leg to complete single limb activities. Therefore, the validity of the measure in truly documenting functional deficits in the patient with a unilateral clubfoot or a less severe bilateral foot, may be suspect. Other researchers have also evaluated motor function ability in children initially treated with Ponseti casting $(62,63)$. While Aulie et al. reported $76 \%$ of patients with clubfoot treated either surgically or with Ponseti casting, were classified with normal motor abilities (62), Lööf suggests global deficits that may affect a child's perception of their quality of life (63). It is imperative to understand the objective of the assessment (global motor function or joint specific), when interpreting the results.

Subsequently, 175 patients with 263 affected clubfeet returned to the gait laboratory at the age of ten years for further assessment (31). Gait analysis was repeated, with the addition of isokinetic muscle strength testing, parent reported outcome questionnaire, and step activity monitoring for one week to measure ambulatory activity in the community. As in previous studies, there were no kinematic difference between patients who did not have surgery for their clubfoot but were treated either with the French PT regimen or by the Ponseti protocol. Compared to normal, there was diminished range of motion of the ankle during gait, specifically a loss of peak plantarflexion. This was expressly seen in patients with intraarticular joint release and most significantly in those who underwent posteriomedial release. Kinetics showed decreased power generation at the ankle, which correlated with isokinetic weakness in the gastroc-soleus muscle. Irrespective of treatment, gastroc-soleus weakness was seen in the affected leg, where even patients with successful Ponseti treatment had an average decreased plantarflexion strength of $38 \%$ compared to controls; however, weakness and loss of ankle power were most notable in feet treated surgically.

Step activity monitors measure ambulatory activity (often reported in step counts and active minutes) and can be used to quantify everyday activity in the community. Such devices have been used in the study of many conditions, such as cerebral palsy, scoliosis and clubfoot $(31,64,65)$. Advanced analysis of ambulatory activity data, has shown the efficacy of distinguishing the type of activity these patients experience in a typical day (65). By assessing intensity and duration of activity bouts (66), we can better understand the quality of their movement. These monitors were used in 106 children with clubfeet and compared to 42 age-matched typically developing children without orthopaedic conditions (31). Interestingly, children with clubfoot did take significantly fewer total steps per day than their peers, although the difference was quite small (less than 10\%). When the parent was asked for his/her perception of function on the Pediatric Outcomes Data Collecting Instrument (67), he/she reported that overall, both operative and nonoperative children scored within normal ranges. The only statistical finding was that children who had full posteromedial release surgery scored lowest on the "global function score".

More detailed functional assessment of foot kinematics, in the adolescent who was treated for clubfoot, is being explored and validated. In small children, a simple marker set including a single marker on the foot at the dorsum of the second metatarsal head is used to measure ankle kinematics and rotation of the foot. In some children with clubfoot, there may be equinus of the hindfoot with dorsiflexion at the mid and forefoot, the so-called "midfoot break". In a simplified kinematic model, ankle sagittal plane kinematics would show normal dorsiflexion. As the foot grows, there is now the capability of using an increased number of smaller markers on the foot and tracking them during gait. In doing so, the ankle and hindfoot motion can now be isolated from the forefoot so that segmental motion of the foot may be measured and compared $(19,28,37,38)$. Early use of a multisegment foot model was used by Theologis et al. in 2003, to assess foot function following clubfoot surgical intervention in children (6.9-14.6 years) (19). Along with decreased plantarflexion power, they reported increased dorsiflexion occurring through the midfoot, with decreased mobility in 
the hindfoot.

This detailed kinematic data can be reliably studied (33) in conjunction with plantar pressure data (50) to gain a deeper understanding of the function of the clubfoot. A recent study by the same group (34), reported multi-segment foot motion along with pedobarograph outcomes in a group of symptomatic patients treated with Ponseti $(n=28)$ or surgery $(n=31)$. Although no differences were shown in range of motion between feet treated with Ponseti or surgery, they did show the hindfoot to have significantly reduced range of motion in the sagittal and coronal planes compared to controls. Pedobarograph results reflected this finding by showing a significant decrease in hindfoot pressure and an increase in midfoot pressure for both CF groups, compared to controls. Symptomatic clubfeet, present similarly whether treated with Ponseti or surgery.

Gait, however, is just one mobility requirement in a child's daily life. The ability to keep up with their peers on the playground and to have the mobility to participate in sports and recreational activities, may be directly affected by limitations in motion. Further application of a multisegment foot model can be applied to functional tasks including hopping and toe rises. This research is currently underway at our institution.

The assessment of the treated clubfoot has markedly changed over the last twenty years. Success and failure of treatment are no longer solely defined by the radiographic measure of the talocalcaneal angle, for example. Nor is a functional result dependent on whether surgery was performed and if revision treatment was subsequently required. Through instrumented gait analysis, much has been learned about the differences in foot function following nonoperative and operative correction of the clubfoot. Clearly, even following successful nonoperative treatment, differences persist compared to normal when evaluating ankle motion and strength. But now clinicians can compare how close to normal a given treatment may allow the child to become.

\section{Conclusions}

The literature has provided much enthusiasm for the adoption of nonoperative treatment of the child with clubfoot. Further knowledge regarding athletic ability, running, and jumping activities is being garnered. As these children complete growth and move into adulthood, future studies will provide insight into the long-term functional effect of nonoperative clubfoot treatment.

\section{Acknowledgments}

Funding: This work was supported by the Scottish Rite Research Fund.

\section{Footnote}

Provenance and Peer Review: This article was commissioned by the Guest Editors (Federico Canavese and Alain Dimeglio) for the series "Clubfoot" published in Annals of Translational Medicine. The article has undergone external peer review.

Reporting Checklist: The authors have completed the Narrative Review reporting checklist. Available at http:// dx.doi.org/10.21037/atm-20-6922

Peer Review File: Available at http://dx.doi.org/10.21037/ atm-20-6922

Conflicts of Interest: Both authors have completed the ICMJE uniform disclosure form (available at http://dx.doi. org/10.21037/atm-20-6922). The series "Clubfoot" was commissioned by the editorial office without any funding or sponsorship. The authors have no other conflicts of interest to declare.

Ethical Statement: the authors are accountable for all aspects of the work in ensuring that questions related to the accuracy or integrity of any part of the work are appropriately investigated and resolved.

Open Access Statement: This is an Open Access article distributed in accordance with the Creative Commons Attribution-NonCommercial-NoDerivs 4.0 International License (CC BY-NC-ND 4.0), which permits the noncommercial replication and distribution of the article with the strict proviso that no changes or edits are made and the original work is properly cited (including links to both the formal publication through the relevant DOI and the license). See: https://creativecommons.org/licenses/by-nc-nd/4.0/.

\section{References}

1. Ponseti IV, Smoley EN. Congenital club foot: The results of treatment. J Bone Joint Surg Am 1963;45:261-344.

2. Laaveg SJ, Ponseti IV. Long-term results of treatment of congenital club foot. J Bone Joint Surg Am 1980;62:23-31. 
3. Bensahel H, Guillaume A, Czukonyi Z, et al. Results of physical therapy for idiopathic clubfoot: a long-term follow-up study. J Pediatr Orthop 1990;10:189-92.

4. Dobbs MB, Morcuende JA, Gurnett CA, et al. Treatment of idiopathic clubfoot: an historical review. Iowa Orthop J 2000;20:59-64.

5. Richards BS, Faulks S, Rathjen KE, et al. A comparison of two nonoperative methods of idiopathic clubfoot correction: the Ponseti method and the French functional (physiotherapy) method. J Bone Joint Surg Am 2008;90:2313-21.

6. Dimeglio A, Canavese F. The French functional physical therapy method for the treatment of congenital clubfoot. J Pediatr Orthop B 2012;21:28-39.

7. Roye BD, Vitale MG, Gelijns AC, et al. Patient-based outcomes after clubfoot surgery. J Pediatr Orthop 2001;21:42-9.

8. Vitale MG, Choe JC, Vitale MA, et al. Patient-based outcomes following clubfoot surgery: a 16-year follow-up study. J Pediatr Orthop 2005;25:533-8.

9. O'Halloran CP, Halanski MA, Nemeth BA, et al. Can Radiographs Predict Outcome in Patients With Idiopathic Clubfeet Treated With the Ponseti Method? J Pediatr Orthop 2015;35:734-8.

10. Richards BS, Faulks S, Razi O, et al. Nonoperatively Corrected Clubfoot at Age 2 Years: Radiographs Are Not Helpful in Predicting Future Relapse. J Bone Joint Surg Am 2017;99:155-60.

11. Otis JC, Bohne WH. Gait analysis in surgically treated clubfoot. J Pediatr Orthop 1986;6:162-4.

12. Yamamoto H, Muneta T, Furuya K. Cause of toe-in gait after posteromedial release for congenital clubfoot. J Pediatr Orthop 1994;14:369-71.

13. Asperheim MS, Moore C, Carroll NC, et al. Evaluation of residual clubfoot deformities using gait analysis. J Pediatr Orthop B 1995;4:49-54.

14. Karol LA, Concha MC, Johnston CE 2nd. Gait analysis and muscle strength in children with surgically treated clubfeet. J Pediatr Orthop 1997;17:790-5.

15. Alkjaer T, Pedersen EN, Simonsen EB. Evaluation of the walking pattern in clubfoot patients who received early intensive treatment. J Pediatr Orthop 2000;20:642-7.

16. Davies TC, Kiefer G, Zernicke RF. Kinematics and kinetics of the hip, knee, and ankle of children with clubfoot after posteromedial release. J Pediatr Orthop 2001;21:366-71.

17. Davies TC, Kiefer G, Zernicke RF. Ankle and first metatarsophalangeal joint dorsiflexion in children with clubfoot. J Pediatr Orthop 2001;21:727-30.

18. Beyaert C, Haumont T, Paysant J, et al. The effect of inturning of the foot on knee kinematics and kinetics in children with treated idiopathic clubfoot. Clin Biomech (Bristol, Avon) 2003;18:670-6.

19. Theologis TN, Harrington ME, Thompson N, et al. Dynamic foot movement in children treated for congenital talipes equinovarus. J Bone Joint Surg Br 2003;85:572-7.

20. O'Brien SE, Karol LA, Johnston CE 2nd. Calcaneus gait following treatment for clubfoot: preliminary results of surgical correction. J Pediatr Orthop B 2004;13:43-7.

21. Muratli HH, Dağli C, Yavuzer G, et al. Gait characteristics of patients with bilateral club feet following posteromedial release procedure. J Pediatr Orthop B 2005;14:206-11.

22. Karol LA, O'Brien SE, Wilson H, et al. Gait analysis in children with severe clubfeet: early results of physiotherapy versus surgical release. J Pediatr Orthop 2005;25:236-40.

23. El-Hawary R, Karol LA, Jeans KA, et al. Gait analysis of children treated for clubfoot with physical therapy or the Ponseti cast technique. J Bone Joint Surg Am 2008;90:1508-16.

24. Sankar WN, Rethlefsen SA, Weiss J, et al. The recurrent clubfoot: can gait analysis help us make better preoperative decisions? Clin Orthop Relat Res 2009;467:1214-22.

25. Karol LA, Jeans K, ElHawary R. Gait analysis after initial nonoperative treatment for clubfeet: intermediate term followup at age 5. Clin Orthop Relat Res 2009;467:1206-13.

26. Gottschalk HP, Karol LA, Jeans KA. Gait analysis of children treated for moderate clubfoot with physical therapy versus the Ponseti cast technique. J Pediatr Orthop 2010;30:235-9.

27. Smith PA, Kuo KN, Graf AN, et al. Long-term results of comprehensive clubfoot release versus the Ponseti method: which is better? Clin Orthop Relat Res 2014;472:1281-90.

28. Mindler GT, Kranzl A, Lipkowski CA, et al. Results of gait analysis including the Oxford foot model in children with clubfoot treated with the Ponseti method. J Bone Joint Surg Am 2014;96:1593-9.

29. Jeans KA, Erdman AL, Jo CH, et al. A Longitudinal Review of Gait Following Treatment for Idiopathic Clubfoot: Gait Analysis at 2 and 5 Years of Age. J Pediatr Orthop 2016;36:565-71.

30. Karol LA, Jeans KA, Kaipus KA. The relationship between gait, gross motor function, and parental perceived outcome in children with clubfeet. J Pediatr Orthop 2016;36:145-51.

31. Jeans KA, Karol LA, Erdman AL, et al. Functional Outcomes Following Treatment for Clubfoot: Ten-Year Follow-up. J Bone Joint Surg Am 2018;100:2015-23. 
32. Tuinsma ABM, Vanwanseele B, van Oorschot L, et al. Gait kinetics in children with clubfeet treated surgically or with the Ponseti method: A meta-analysis. Gait Posture 2018;66:94-100.

33. McCahill J, Stebbins J, Koning B, et al. Repeatability of the Oxford Foot Model in children with foot deformity. Gait Posture 2018;61:86-9.

34. McCahill JL, Stebbins J, Harlaar J, et al. Foot function during gait and parental perceived outcome in older children with symptomatic club foot deformity. Bone Joint Open 2020;1:384-91.

35. Widhe T, Berggren L. Gait analysis and dynamic foot pressure in the assessment of treated clubfoot. Foot Ankle Int 1994;15:186-90.

36. Hee HT, Lee EH, Lee GS. Gait and pedobarographic patterns of surgically treated clubfoot. J Foot Ankle Surg 2001;40:287-94.

37. Graf A, Hassani S, Krzak J, et al. Long-term outcome evaluation in young adults following clubfoot surgical release. J Pediatr Orthop 2010;30:379-85.

38. Church C, Coplan JA, Poljak D, et al. A comprehensive outcome comparison of surgical and Ponseti clubfoot treatments with reference to pediatric norms. J Child Orthop 2012;6:51-9.

39. Cooper DM, Dietz FR. Treatment of idiopathic clubfoot. A thirty-year follow-up note. J Bone Joint Surg Am 1995;77:1477-89.

40. Huang YT, Lei W, Zhao L, et al. The treatment of congenital club foot by operation to correct deformity and achieve dynamic muscle balance. J Bone Joint Surg Br 1999;81:858-62.

41. Thometz JG, Liu XC, Tassone JC, et al. Correlation of foot radiographs with foot function as analyzed by plantar pressure distribution. J Pediatr Orthop 2005;25:249-52.

42. Favre P, Exner GU, Drerup B, et al. The contralateral foot in children with unilateral clubfoot: a study of pressures and forces involved in gait. J Pediatr Orthop 2007;27:54-9.

43. Sinclair MF, Bosch K, Rosenbaum D, et al.

Pedobarographic analysis following Ponseti treatment for congenital clubfoot. Clin Orthop Relat Res 2009;467:1223-30.

44. Jeans KA, and Karol LA. Plantar Pressures following the Ponseti and French Physiotherapy Methods for Clubfoot. J Pediatr Orthop 2010;30:82-9.

45. Salazar-Torres JJ, McDowell BC, Humphreys LD, et al. Plantar pressures in children with congenital talipes equino varus--a comparison between surgical management and the Ponseti technique. Gait Posture 2014;39:321-7.
46. Jeans KA, Tulchin-Francis K, Crawford L, et al. Plantar pressures following anterior tibialis tendon transfers in children with clubfoot. J Pediatr Orthop 2014;34:552-8.

47. Gray K, Burns J, Little D, et al. Is tibialis anterior tendon transfer effective for recurrent clubfoot? Clin Orthop Relat Res 2014;472:750-8.

48. Holt JB, Oji DE, Yack HJ, et al. Long-term results of tibialis anterior tendon transfer for relapsed idiopathic clubfoot treated with the Ponseti method: a follow-up of thirty-seven to fifty-five years. J Bone Joint Surg Am 2015;97:47-55.

49. Wallace J, White H, Xi J, Kryscio R, et al. Pedobarographic changes in Ponseti-treated clubfeet with and without anterior tibialis tendon transfer: changes due to growth and surgical intervention. J Pediatr Orthop B 2016;25:89-95.

50. Giacomozzi C, Stebbins JA. Anatomical masking of pressure footprints based on the Oxford Foot Model: validation and clinical relevance. Gait Posture 2017;53:131-8.

51. Jeans KA, Erdman AL, Karol LA. Plantar Pressures After Nonoperative Treatment for Clubfoot: Intermediate Follow-up at Age 5 Years. J Pediatr Orthop 2017;37:53-8.

52. Erdman AL, Jeans KA, Karol LA. Plantar Pressures Following Surgical Release in Children with Clubfoot: Comparison of Posterior Release, Posteromedial Release, and Nonoperative Correction. J Pediatr Orthop 2020;40:e634-40.

53. Masrouha KZ, Moses MJ, Sala DA, et al. The Validity of Patient-reported Outcome Measurement Information System (PROMIS) Parent Proxy Instruments to Assess Function in Children with Talipes Equinovarus. J Pediatr Orthop 2019;39:e787-e790.

54. Brand RA, Laaveg SJ, Crowninshield RD, et al. The center of pressure path in treated clubfoot. Clin Orthop Relat Res 1981;160:43-7.

55. Aronson J, Puskarich CL. Deformity and disability from treated clubfoot. J Pediatr Orthop 1990;10:109-19.

56. Masse P. Le traitement du pied bot par la methode "functionnelle"”, in Cahier d'enseignement de la SOFCOT. Paris, France: Expansion Scientific 1977;3:51-6.

57. Bill PL, Versfeld GA. Congenital clubfoot: an electromyographic study. J Pediatr Orthop 1982;2:139-42.

58. Ezra E, Hayek S, Gilai AN, et al. Tibialis anterior tendon transfer for residual dynamic supination deformity in treated club feet. J Pediatr Orthop B 2000;9:207-11.

59. Wicart P, Richardson J, Maton B. Adaptation of gait initiation in children with unilateral idiopathic clubfoot 
following conservative treatment. J Electromyogr Kinesiol 2006;16:650-60.

60. Watts HG. Gait laboratory analysis for preoperative decision making in spastic cerebral palsy: is it all it's cracked up to be? J Pediatr Orthop 1994;14:703-4.

61. Folio R and Fewell R. Peabody Developmental Motor Scales (2nd ed.) Austin TX: Pro-Ed; 2000.

62. Aulie VS, Halvorsen VB, Brox JI. Motor abilities in 182 children treated for idiopathic clubfoot: a comparison between the traditional and the Ponseti method and controls. J Child Orthop 2018;12:383-9.

63. Lööf $\mathrm{E}$. Additional challenges in children with idiopathic clubfoot: is it just the foot? J Child Orthop 2019;13:245-51.

64. Bjornson KF, Beiza B, Kartin D, et al. Ambulatory physical activity performance in youth with cerebral palsy and youth who are developing typically. Phys Ther 2007;87:248-57.

Cite this article as: Karol LA, Jeans KA. This is a narrative review of the functional evaluation of clubfoot treatment with gait analysis. Ann Transl Med 2021;9(13):1105. doi: 10.21037/ atm-20-6922
65. Stevens W, Jeans KA, Tulchin-Francis K, et al. Community Ambulatory Activity and Gross Motor Function Following Treatment for Clubfoot at age 10yrs. Pediatric Orthopaedic Society of North America proceedings, 2017, Barcelona, Spain.

66. Tulchin-Francis K, Stevens W Jr, Jeans KA. Intensity and duration of activity bouts decreases in healthy children between 7 and 13 years of age: a new, higher resolution method to analyze StepWatch Activity Monitor data. Physiol Meas 2014;35:2239-54.

67. Daltroy LH, Liang MH, Fossel AH, et al. Pediatric Outcomes Instrument Development Group. Pediatric Orthopaedic Society of North America. The POSNA pediatric musculoskeletal functional health questionnaire: report on reliability, validity, and sensitivity to change. J Pediatr Orthop 1998;18:561-71. 